\title{
Plant In vitro Culture goes Nano: Nanosilver-Mediated Decontamination of EX vitro Explants
}

\author{
Nasser Mahna ${ }^{1 *}$, Sepideh Zununi Vahed ${ }^{2,3,4}$ and Sajjad Khani',3 \\ ${ }^{1}$ Department of Horticultural Sciences, Faculty of Agriculture, University of Tabriz, Tabriz, Iran \\ ${ }^{2}$ Research Center for Pharmaceutical Nanotechnology, Faculty of Pharmacy, Tabriz University of Medical Sciences, Tabriz, Iran \\ ${ }^{3}$ School of Advanced Biomedical Sciences, Tabriz University of Medical Sciences, Tabriz, Iran \\ ${ }^{4}$ Faculty of Biology, Tarbiat Moallem Azarbayjan University, Tabriz, Iran
}

\begin{abstract}
Plant tissue culture is a basic and fundamental component of plant biotechnology, and progress in different fields of biotechnology greatly depends on the improvement of this technique. Nowadays, nanomaterials especially Nanosilver [NS], are regularly being used as an antimicrobial agent in medical and environmental fields. In order to assay the efficiency of NS in sterilizing plant seeds and fragile tissues, such as leaf and cotyledon, two important model plants, Arabidopsis and tomato, as well as potato as an important cultivated crop, were used as explants in this study. Briefly, samples soaked in different concentrations of NS with various exposure times, and then transferred onto the MS medium. Results showed that at lower concentrations, NS could function as an antimicrobial agent with no side effect on the explant viability, and consequently, all decontaminated seeds germinated, and leaf and cotyledon explants survived.
\end{abstract}

Keywords: Arabidopsis; Decontamination; Nanosilver; Plant in vitro culture; Potato; Tomato

\section{Introduction}

Currently, plant tissue culture has direct commercial importance, and its application in basic research such as cell biology, genetics, biochemistry and biotechnology is evidence for its usefulness [1]. Tissue culture not only provides a method for mass propagation, but also makes possible the production of disease-free and genetically modified plants. It also provides a way for secondary metabolite production [2,3]. Despite all advantages of this technique, some methodological obstacles, mainly contamination of explants, hinders its exploiting as an efficient technique for biotechnological research. By the way, internal and external contamination of plant tissues turns out to be a prevailing problem, because microorganisms, mostly fungi and bacteria, can grow much faster than plant cells and take up all the nutrients, preventing the plants from growing [4].

Although there are a variety of techniques to minimize the possibility of bacterial and fungal contaminations during in vitro propagation, such as meristem culture (the pathogen-free part of the plant) and repetitive subcultures, designing a more efficient approach to sterilize plant tissues still seems necessary to eliminate labor intensive trial and errors, and time-consuming decontamination procedures. In order to eliminate the persistent fungal and bacterial contaminations, treatment with antibiotics and antifungal agents may be used to lessen the contamination; whereas it has been reported that antibiotics are normally phytotoxic, and have an inhibitory effect on multiplication, callus induction, regeneration, and explant survival $[5,6]$. On the other hand, lack of an optimal protocol for sterilization of field-, orchardor greenhouse-derived (ex vitro) explants may result in a paucity of samples for further research.

The antimicrobial effects of silver against a broad range of microorganisms have been noticed since ancient times, and nowadays, silver nanoparticles having a very small size down to $1 \mathrm{~nm}$, have numerous medical and pharmaceutical applications [7-10]. At nanoscale, silver exhibits surprisingly unusual physical, chemical and biological properties. Excellent functional durability, heat resistance, ease of application, wide range of utility, leaving no resistant bacteria, being environmental friendly and non-toxic, wide range of antimicrobial spectrum, cost-effective manufacturing process and availability, are the significant characteristics of NS $[7,11]$.

In contrast to the attention paid to new applications of NS in medicine, only negligible studies remarked the application of NS in plant biotechnology. Therefore, because of the importance of plant cell and tissue culture, and to tackle the problems such as contamination as a dominant barrier in plant tissue culture, in this research, we have evaluated the decontaminating efficiency of silver nanoparticles on in vivo-derived explants.

In a recent research, using nanosilver has been reported to be an efficient method for decontamination of valerian explants; however, a complete decontamination was never obtained [12]. So, this the first report in which a complete decontamination has been achieved through NS treatment.

\section{Materials and Methods}

To evaluate the efficiency of NS in sterilizing plant seeds and tissues, explants from Arabidopsis thaliana cv. Col-0 and tomato (Lycopersicon esculentum cv. Micro-Tom), as well as potato (Solanum tuberosum), as an important cultivated crop were used in this study. The NS used in this research was Nanocid L-2000 (Nanonasb Co., Tehran, Iran), whose properties has been shown in table 1 . Different concentrations of NS were used $(100,250,500,1000$ and $2000 \mathrm{ppm})$, as well as five exposure times $(5,10,20,30$ and $60 \mathrm{~min})$. Each of 25 treatments was carried

*Corresponding author: Nasser Mahna, Department of Horticultural Sciences, Faculty of Agriculture, University of Tabriz, Tabriz, Iran, Tel: 98-411-3392027; Fax: +98-411-3345332; E-mail: mahna@tabrizu.ac.ir

Received December 12, 2012; Accepted February 01, 2013; Published February 04, 2013

Citation: Mahna N, Vahed SZ, Khani S (2013) Plant In vitro Culture goes Nano: Nanosilver-Mediated Decontamination of Ex vitro Explants. J Nanomed Nanotechol 4: 161. doi:10.4172/2157-7439.1000161

Copyright: ( 2013 Mahna N, et al. This is an open-access article distributed unde the terms of the Creative Commons Attribution License, which permits unrestricted use, distribution, and reproduction in any medium, provided the original author and source are credited. 


\begin{tabular}{|c|c|}
\hline \multicolumn{2}{|c|}{ Physical properties } \\
\hline Phase & solid \\
\hline Density (near r.t.) & $10.49 \mathrm{~g} / \mathrm{cm}^{3}$ \\
\hline Liquid density at m.p. & $9.320 \mathrm{~g} / \mathrm{cm}^{3}$ \\
\hline Melting point & $1234.93 \mathrm{~K}\left(961.78^{\circ} \mathrm{C}, 1763.2^{\circ} \mathrm{F}\right)$ \\
\hline Boiling point & $2435 \mathrm{~K}\left(2162^{\circ} \mathrm{C}, 3924^{\circ} \mathrm{F}\right)$ \\
\hline Heat of fusion & $11.28 \mathrm{~kJ} / \mathrm{mol}$ \\
\hline Heat of vaporization & $258 \mathrm{~kJ} / \mathrm{mol}$ \\
\hline Heat capacity & $\left(25^{\circ} \mathrm{C}\right) 25.350 \mathrm{~J} /(\mathrm{mol} \mathrm{K})$ \\
\hline & \\
\hline & Atomic Properties \\
\hline Crystal structure & cubic face centered \\
\hline Oxidation states & $1($ amphoteric oxide) \\
\hline Electronegativity & $1.93($ Pauling scale $)$ \\
\hline Ionization energies & \\
\hline 1st: & $731.0 \mathrm{~kJ} / \mathrm{mol}$ \\
\hline 2nd: & $2070 \mathrm{~kJ} / \mathrm{mol}$ \\
\hline 3rd: & $3361 \mathrm{~kJ} / \mathrm{mol}$ \\
\hline Atomic radius & $160 \mathrm{pm}$ \\
\hline Atomic radius (calc.) & $165 \mathrm{pm}$ \\
\hline Covalent radius & $153 \mathrm{pm}$ \\
\hline Van der Waals radius & $172 \mathrm{pm}$ \\
\hline
\end{tabular}

Table 1: The properties of NS (Nanocid L-2000) used in this study.

out in a petri plate, with at least 30 seeds of Arabidopsis as replicates and two petri plates as control, in which no NS was used. To evaluate the effect of NS on seeds, the percentages of germinated seeds were calculated. In the other experiment, tomato cv. Micro-Tom leaves were collected from ex vitro plants. Cotyledons of greenhouse grown tomato cv. Micro-Tom were treated with NS at different concentrations, ranging from 10, 100, 250 and $500 \mathrm{ppm}$ for different periods (i.e. 5, 10, $20 \mathrm{~min}$ ), with four replicates. The cotyledons treated in sterile distilled water were used as control. After treatment, the cotyledons and seeds of control and experimental samples were thoroughly washed in sterile distilled water, then placed on MS medium [13], containing $0.8 \%$ agar at $24 \pm 2^{\circ} \mathrm{C}$, under $16 / 8 \mathrm{~h}$ photoperiod.

The percentages of infected explants were recorded 10 days after culture for Lycopersicon esculentum cv. Micro-Tom. Contamination of Arabidopsis thaliana seeds were evaluated 7 days after their germination, when the four-leaved plantlets were formed. The experiment was conducted as a completely randomized design in a factorial arrangement with four replications.

\section{Results and Discussion}

New methods for preventing contamination in plant in vitro culture by means of antibiotics, repeated subcultures, flexible container system, density gradient centrifugation, low free-water medium, acidification, and egg white lysozyme have been reviewed in the book, edited by Herman [14]. Due to its strong antimicrobial activity, use of NS is becoming more and more widespread in medicine and related applications. To evaluate the efficiency of NS in decontaminating diverse kinds of explants, we used different concentrations of NS with different exposure times to find the best sterilization treatment. Using NS seems more convenient and less toxic than using antibiotics in the medium. Moreover, other methods for controlling the infection like microbial culture filtrate [15], and acidification of the medium [16], are time consuming. Satisfactory antimicrobial activity obtained in this research is consistent with the previous results in the literature $[17,8]$. Abdi et al. [12] have used NS for decontamination of valerian explants. Also, there is another report of successful disinfestation of Araucaria excelsa explants in tissue culture carried out by Sarmast et al. [18].
Our results showed that all used concentrations and exposure times of NS were efficient in decontaminating the Arabidopsis plant seeds and tomato plant cotyledons. The controls were all contaminated when examined after two weeks. However, the concentration of the solutions was a critical parameter. When NS was used at lower concentrations of 100 ppm for Arabidopsis seeds, it could function as an antimicrobial agent leaving no harmful effect on seeds and their germination, so that all were germinated. It has been illustrated that the toxicity of NS to microbial cells is apparent even at very low concentrations [19]. Increasing the concentration of NS decreased the germination percentage of the seeds, and finally in the concentrations of 1000 and $2000 \mathrm{ppm}$, none of the seeds were germinated (Table 2). Treating explants with 10 ppm NS was not effective in their decontamination.

We obtained similar results with the seeds of rapeseed plant, with the concentration of $150 \mathrm{ppm}$. It seems that at higher concentrations, NS is toxic for plant seeds and hampers seed germination. The same results obtained from potato leaves, so that NS in all exploited concentrations and exposure times was able to decontaminate the leaf explants; however, at the concentration of $500 \mathrm{ppm}$ survival of the samples diminished (Table 3). At this concentration, when the exposure time reached 20 minutes, none of the explants survived.

In the experiment of tomato cotyledons, efficient decontamination of cotyledons occurred with all three concentrations of NS in three exposure times, while complete survival was observed only at lower concentrations and exposure times. The survival decreased with increasing the factor levels, and finally at $100 \mathrm{ppm}$, and both 2.5 and 5 min, all explants died (Table 4).

As a matter of fact, providing enough sterile fast growing explants

\begin{tabular}{|c|c|c|c|}
\hline \multirow{2}{*}{ Time (min) } & \multirow{2}{*}{$\begin{array}{l}\text { NS concentration } \\
(p p m)\end{array}$} & \multicolumn{2}{|c|}{ Arabidopsis seed } \\
\hline & & \multirow{2}{*}{$\begin{array}{c}\text { Decontaminated (\%) } \\
0\end{array}$} & \multirow{2}{*}{$\begin{array}{c}\text { Survived }^{*}(\%) \\
100\end{array}$} \\
\hline \multicolumn{2}{|c|}{ Control } & & \\
\hline \multirow[t]{5}{*}{5} & 100 & 100 & $99 \pm 1$ \\
\hline & 250 & 100 & 100 \\
\hline & 500 & 100 & $99 \pm 0.5$ \\
\hline & 1000 & 100 & $98 \pm 0.6$ \\
\hline & 2000 & 100 & $99 \pm 0.7$ \\
\hline \multirow[t]{5}{*}{10} & 100 & 100 & $99 \pm 0.4$ \\
\hline & 250 & 100 & $97 \pm 1.2$ \\
\hline & 500 & 100 & $96 \pm 2.1$ \\
\hline & 1000 & 100 & $98 \pm 1.0$ \\
\hline & 2000 & 100 & $99 \pm 0.9$ \\
\hline \multirow[t]{5}{*}{20} & 100 & 100 & $97 \pm 1.3$ \\
\hline & 250 & 100 & $1 \pm 0.2$ \\
\hline & 500 & 100 & $1.3 \pm 0.3$ \\
\hline & 1000 & 100 & 0 \\
\hline & 2000 & 100 & 0 \\
\hline \multirow[t]{5}{*}{30} & 100 & 100 & 0 \\
\hline & 250 & 100 & 0 \\
\hline & 500 & 100 & 0 \\
\hline & 1000 & 100 & 0 \\
\hline & 2000 & 100 & 0 \\
\hline \multirow[t]{5}{*}{60} & 100 & 100 & 0 \\
\hline & 250 & 100 & 0 \\
\hline & 500 & 100 & 0 \\
\hline & 1000 & 100 & 0 \\
\hline & 2000 & 100 & 0 \\
\hline
\end{tabular}

*mean \pm standard deviation

Table 2: The effect of different concentrations and exposures of NS on Arabidopsis 


\begin{tabular}{|c|c|c|c|}
\hline \multirow{2}{*}{ Time (min) } & \multirow{2}{*}{ Concentration (ppm) } & \multicolumn{2}{|c|}{ Potato leaf } \\
\cline { 2 - 4 } & & Decontaminated (\%) & Survived (\%) \\
\hline 5 & 10 & 0 & 0 \\
\hline & 100 & 100 & 100 \\
\hline & 250 & 100 & 100 \\
\hline & 500 & 100 & $74 \pm 3$ \\
\hline 10 & 10 & 0 & 0 \\
\hline & 100 & 100 & 100 \\
\hline & 250 & 100 & 100 \\
\hline & 500 & 100 & 0 \\
\hline & 10 & 0 & 100 \\
\hline & 100 & 100 & $65 \pm 9$ \\
\hline & 250 & 100 & 0 \\
\hline
\end{tabular}

Table 3: The effect of different concentrations and exposures of NS on potato leaves.

\begin{tabular}{|c|c|c|c|}
\hline \multirow{2}{*}{ Time (min) } & \multirow{2}{*}{ Concentration (ppm) } & \multicolumn{2}{|c|}{ Tomato cotyledon } \\
\hline & & Decontaminated (\%) & Survived (\%) \\
\hline \multirow[t]{3}{*}{1} & 25 & $98 \pm 1.9$ & 100 \\
\hline & 50 & $99 \pm 0.7$ & $99 \pm 0.9$ \\
\hline & 100 & 100 & $69 \pm 4.6$ \\
\hline \multirow[t]{3}{*}{2.5} & 25 & $97 \pm 2.3$ & $97 \pm 2.1$ \\
\hline & 50 & $98 \pm 1.8$ & $99 \pm 0.5$ \\
\hline & 100 & 100 & 0 \\
\hline \multirow[t]{3}{*}{5} & 25 & 100 & $65 \pm 3.3$ \\
\hline & 50 & 100 & $32 \pm 5.5$ \\
\hline & 100 & 100 & 0 \\
\hline
\end{tabular}

Table 4: The effect of different concentrations and exposures of NS on tomato cotyledons.

for plant regeneration experiments leading to transgenic plants is a slowing step of plant genetic engineering. In order to evaluate the hypothesis that we can take such explants from ex vitro and field grown plants for regeneration attempts, we carried out another experiment. Here, we exploited tomato cotyledons and potato leaves again with different concentrations and exposure times. The results showed that decontamination capacity of lower concentration of NS (10 ppm) was not adequate, but higher concentrations were strong enough to kill germs, and no contamination observed after 10 days. There was no significant change in the morphology and viability of explants; nevertheless, the effect of different concentrations of NS on the potential of tomato cotyledons and potato leaves to regenerate plants is yet to be elucidated. This complete decontamination of plant tissues, as shown in all experiments of this report, was never observed before in a similar research by Abdi et al. [12].

The possible mechanism through which NS acts as a disinfectant agent in this process may lie on the properties of silver. Ag ions interact with a number of components of bacterial, fungal and protozoal cells. Although the inhibitory mechanism of NS is not obviously distinguished, three possible mechanisms have been proposed for inhibition of microorganisms by silver nanoparticles: interfering with electron transport, binding to DNA, and interaction with the cell membrane $[8,20-22]$. The formation of complexes with sulfhydryl groups can inactivate vital cell surface enzymes and hinder the respiration at the cell membrane $[8,20]$. Inducing a massive proton leakage through membrane, discharging $\mathrm{K}^{+}$ions, inhibition of energydependent $\mathrm{Na}$ transport in membrane, inhibition of cell division and damaging bacterial cell envelopes, interaction with hydrogen bonding processes are also recorded as antimicrobial actions of NS [20,2325]. Nano-Ag can also disturb the integrity of the plasma membrane of fungal cell [26]. The association of silver nanoparticles with the envelope of certain viruses has been suggested to prevent them from being infective [10].

It can be concluded that a colloidal solution of NS at lower concentrations (e.g. $100 \mathrm{ppm}$ ) can be used as a disinfectant for plant seeds, especially for in vitro cultures; however, at high concentrations, it hinders seed germination, maybe due to its toxicity against eukaryotic cells. In tomato plant, use of NS at more than $100 \mathrm{ppm}$ could decontaminate ex vitro leaves.

Although the cytotoxicity of nanoparticles towards mammalian germ line stem cells has been identified, the effect of NS on plant growth is still unknown, and only few studies have been reported $[7,27,28]$. It is reported that the treated meristem cells showed various types of chromosomal and mitotic abnormalities, such as fragments, C-metaphase, stickiness, laggard, anaphasic bridge, and disturbed anaphase [29]. These abnormalities were observed in a dose and duration dependent manner. So, nanosilver may cause potential damage to the genetic material in higher concentration, and therefore, the use of nanosilver in plant cell culture warrants a detail toxicological investigation to justify its safety. Unique interactions with bacteria and viruses have been demonstrated of silver nanoparticles of certain size ranges and shapes [7].

Finally, NS can be an efficient tool for removing contaminants from plant tissues, only if the right dose and exposure time are to be used. Nevertheless, it has not yet become a universal decontamination agent. Therefore, to extend its use in in vitro culture of other plants, further investigations are being conducted on diverse plant species and different explants by the authors.

\section{Acknowledgments}

The authors would like to acknowledge the Nano Nasb Pars Company (Tehran, Iran), for providing NS, and Plant tissue culture lab Head, Dr. MotallebiAzar, for providing lab facilities and space.

\section{References}

1. Gamborg OL (2002) Plant tissue culture: Biotechnology Milestones. In Vitro Cell Dev Biol Plant 38: 84-92.

2. Khosroushahi AY, Valizadeh M, Ghasempour A, Khosrowshahli M, Naghdibadi $\mathrm{H}$, et al. (2006) Improved Taxol production by combination of inducing factors in suspension cell culture of Taxusbaccata. Cell Biollnt 30: 262-269.

3. Murashige T (1974) Plant propagation through tissue cultures. Ann Rev Plant Physiol 25: 135-166.

4. Cassells AC (1991) Problems in tissue culture: Culture contamination In: Micropropagation: technology and application (Eds. Debergh PC and Zimmerman RH), Springer.

5. Leifert C, Camotta H, Waites WM (1992) Effect of combinations of antibiotics on micropropagatedClematis, Delphinium, Hosta, Iris and Photinia. Plant Cell Tissue Organ Cult 29: 153-160

6. Teixeirada Silva JA, Nhut DT, Tanaka M, Fukai S (2003) The effect of antibiotics on the in vitro growth response of chrysanthemum and tobacco stem transverse thin cell layers (tTCLS). SciHortic 97: 397-410.

7. Chen X, Schluesener HJ (2008) Nanosilver: a nanoproduct in medical application. Toxicol Lett 176: 1-12.

8. Sondi I, Salopek-Sondi B (2004) Silver nanoparticles as antimicrobial agent: a case study on E. coli as a model for Gram-negative bacteria. J Colloid Interface Sci 275: 177-182.

9. Tiwari DK, Behari J, Sen P (2008) Application of nanoparticles in waste wate treatment. World Appl Sci J 3: 417-433.

10. Elechiguerra JL, Burt JL, Morones JR, Camacho-Bragado A, Gao X, et al (2005) Interaction of silver nanoparticles with HIV-1. J Nanobiotechnology 3: 6 . 
Citation: Mahna N, Vahed SZ, Khani S (2013) Plant In vitro Culture goes Nano: Nanosilver-Mediated Decontamination of Ex vitro Explants. J Nanomed Nanotechol 4: 161. doi:10.4172/2157-7439.1000161

11. Lansdown AB (2002) Silver. I: Its antibacterial properties and mechanism of action. J Wound Care 11: 125-130.

12. Abdi G, Salehi H, Khosh-Khui M (2008) Nano silver: A novel nanomaterial for removal of bacterial contaminants in valerian (Valerianaofficinalis L.) tissue culture. Acta Physiol Plant 30: 709-714.

13. Murashige $T$, Skoog $F$ (1962) A revised medium for rapid growth and bioassays with tobacco tissue cultures. Physiol Plant 15: 473-497.

14. Herman EB (1996) Microbial contamination of plant tissue cultures. Agritech Consultants Inc, Shrub Oak, USA.

15. Hussain S, Lane SD, Price DN (1994) A preliminary evaluation of the use of microbial culture filtrates for the control of contaminants in plant tissue culture systems. Plant Cell Tissue Organ Cult 36: 45-51.

16. Leifert C, Waites B, Keetley JW, Wright SM, Nicholas JR, et al. (1994) Effect of medium acidification on filamentous fungi, yeasts and bacterial contaminants in Delphinium tissue cultures. Plant Cell Tissue Organ Cult 42:149-155.

17. Nomiya K, Yoshizawa A, Tsukagoshi K, Kasuga NC, Hirakava S, et al. (2004) Synthesis and structural characterization of silver (I), aluminium (III) and cobalt (II) complexes with 4-isopropyltropolone (hinokitiol) showing noteworthy biological activities. Action of silver (I)-oxygen bonding complexes on the antimicrobial activities. J Inorg Biochem 98:46-60.

18. Sarmast MK, Salehi H, Khosh-Khui M (2011) Nano silver treatment is effective in reducing bacterial contaminations of Araucaria excelsa $\mathrm{R}$. Br. var. glauca explants. Acta Biol Hung 62: 477-484

19. Matsumura Y, Yoshikata K, Kunisaki S, Tsuchido T (2003) Mode of bactericidal action of silver zeolite and its comparison with that of silver nitrate. Appl Environ Microbiol 69: 4278-4281.

20. Jung WK, Koo HC, Kim KW, Shin S, Kim SH, et al. (2008) Antibacterial activity and mechanism of action of thesilver ion in Staphylococcus aureus and Escherichia coli.Appl Environ Microbiol 74: 2171-2178.

21. Yakabe $Y$, Sano T, Ushio H, Yasumaga T (1980) Kinetic studies of the interaction between silver ion and deoxyribonucleic acid. Chem Lett 9: 373-376.

22. Batarseh KI (2004) Anomaly and correlation of killing in the therapeutic properties of silver (I) chelation with glutamic and tartaric acids. J Antimicrob Chemother 54: 546-548.

23. Dibrov P, Dzioba J, Gosink KK, Häse CC (2002) Chemiosmotic mechanism of antimicrobial activity of $\mathrm{Ag}(+)$ in Vibrio cholerae. Antimicrob Agents Chemother 46: $2668-2670$.

24. Richards RM, Odelola HA, Anderson B (1984) Effect of silver on whole cells and spheroplasts of a silver resistant Pseudomonas aeruginosa.Microbios 39 151-157.

25. Russell AD, Hugo WB (1994) Antimicrobial activity and action of silver. Prog Med Chem 31: 351-370.

26. Kim KJ, Sung WS, Suh BK, Moon SK, Choi JS, et al. (2009) Antifungal activity and mode of action of silver nano-particles on Candida albicans. Biometals 22 235-242.

27. Panyala NR, Pena-Mendez EM, Havel J (2008) Silver or silver nanoparticles: A hazardous threat to the environment and human health? J Appl Biomed 6 : 117-129.

28. Braydich-Stolle L, Hussain S, Schlager JJ, Hofmann MC (2005) In vitro cytotoxicity of nanoparticles in mammalian germline stem cells. Toxicol Sci 88 412-419.

29. Babu K, Deepa M, Shankar SG, Rai S (2008) Effect of nano-silver on cell division and mitotic chromosomes: A prefatory siren. Internet $\mathrm{J}$ Nanotechno 2: 2 . 